George D. Liatsos, MD, PhD

Staff Consultant A, Department of Internal Medicine,

"Hippokration" General Hospital, Athens, Greece
Emmanouil Koullias, MD

Internist, Department of Internal Medicine,

"Hippokration" General Hospital, Athens, Greece

\title{
Exanthem and enanthem with fever and dyspnea
}

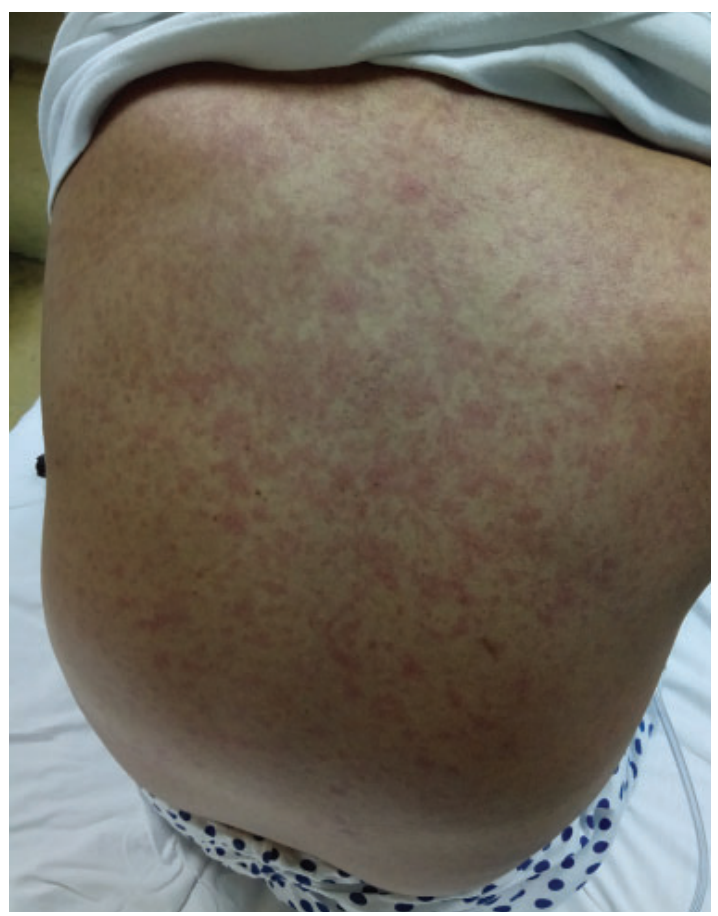

Figure 1. Erythematous, maculopapular, blanching rash on the trunk.

\begin{abstract}
49-YeAR-Old WOMAN PRESENTED with a 5-day history of high fever, productive cough, mild dyspnea, malaise, generalized myalgias, and conjunctivitis. Hours before admission she developed a maculopapular rash. She had been diagnosed 2 years earlier with decompensated liver cirrhosis due to autoimmune hepatitis-primary biliary cholangitis overlap syndrome and was currently being treated with prednisolone, azathioprine, and ursodeoxycholic acid.
\end{abstract}

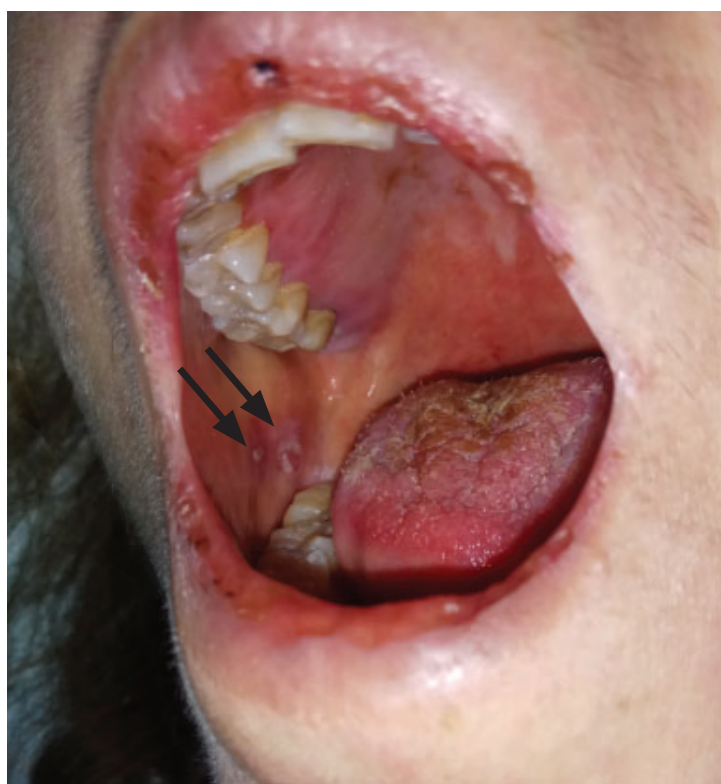

Figure 2. Koplik spots (black arrows), whitish, grayish, or bluish elevations of 1 to 3 $\mathrm{mm}$ with an erythematous base on the buccal mucosa opposite the molars.

\section{WORKUP AND HOSPITAL COURSE}

On examination, her temperature was $38.3^{\circ} \mathrm{C}$ $\left(100.9^{\circ} \mathrm{F}\right)$, heart rate 92 beats per minute, blood pressure 100/68 $\mathrm{mm} \mathrm{Hg}$, respiratory rate 24 breaths per minute, and oxygen saturation $92 \%$ on ambient air. An erythematous, maculopapular, blanching rash was noted on the face and trunk (Figure 1), as well as enanthem on the buccal mucosa opposite the molars (Figure 2). Auscultation detected basilar fine crackles in both lungs. A firm liver was palpable 2 to 3 fingers below the right costal margin without tenderness. The rest of the

\section{Koplik spots are considered pathognomonic for measles}




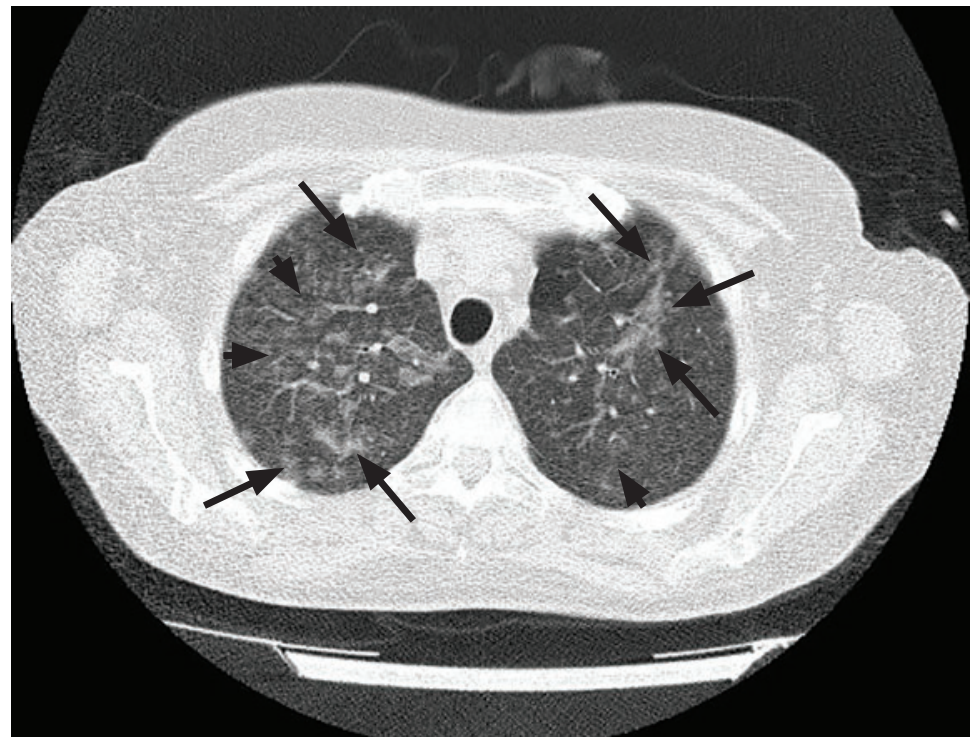

Figure 3. Computed tomography of the lungs revealed bilateral infiltrates (arrows) and ground-glass opacities (arrowheads) mainly in the upper lobes.

physical examination was unremarkable.

Laboratory testing revealed leukopenia, thrombocytopenia, and increased serum levels of aspartate aminotransferase, lactate dehydrogenase, creatine kinase, gamma-glutamyl transferase, and total bilirubin.

The patient's dyspnea deteriorated significantly over the next 2 days, accompanied by high fever, with temperatures of $39.6^{\circ} \mathrm{C}$ to $40.5^{\circ} \mathrm{C}\left(103.3^{\circ} \mathrm{F}\right.$ to $\left.104.9^{\circ} \mathrm{F}\right)$. The initial findings on auscultation worsened and included diffuse bilateral crackles. Arterial blood gas analysis revealed hypoxemia $\left(\mathrm{PaO}_{2} 59 \mathrm{~mm} \mathrm{Hg}\right.$, $\mathrm{PCO}_{2} 27 \mathrm{~mm} \mathrm{Hg}$ ), while she was breathing $3 \mathrm{~L}$ of oxygen per minute by nasal cannula.

Computed tomography of the lungs revealed bilateral infiltrates and ground-glass opacities in the upper lobes (Figure 3). Serologic testing by enzyme-linked immunosorbent assay confirmed the presence of positive immunoglobulin $\mathrm{M}$ antibodies against measles virus. She was treated with $40 \%$ oxygen through a face mask, intravenous levofloxacin, and oral ribavirin. As the enanthem (Koplik spots) prevented the patient from consuming adequate fluids and food, supportive care was provided including D/W $5 \%$ daily by intravenous infusion. The patient was discharged 1 week later in good condition, and at a follow-up visit 1 month after discharge, she was asymptomatic.

\section{DISCUSSION}

Measles is a highly contagious viral illness with a $90 \%$ transmission rate to susceptible individuals. The majority of deaths are from pneumonitis or encephalitis, while the most common complication is diarrhea. During the 2018 measles outbreak in Europe, tens of thousands of cases were reported, with twothirds of patients requiring hospitalization. ${ }^{1}$

The incubation period for measles is 8 to 12 days $^{2}$ and begins after virus entry via respiratory mucosa or conjuctivae. The virus replicates locally, spreads to regional lymphatic tissues, and is then thought to be disseminated to other reticuloendothelial sites through the blood stream ("primary viremia"). ${ }^{3}$ The prodromal phase is defined by the appearance of symptoms that typically include fever, malaise, and anorexia, followed by conjunctivitis that may be accompanied by lacrimation or photophobia, coryza, and cough., ${ }^{2,3}$ Respiratory symptoms result from mucosal inflammation from viral infection of epithelial cells.

Prodromal symptoms typically intensify a few days before exanthem appears. Around 48 hours before the onset of exanthem, patients may develop enanthem characterized by Koplik spots, whitish, grayish, or bluish elevations of 1 to $3 \mathrm{~mm}$ with an erythematous base, typically on the buccal mucosa opposite the molars. Koplik spots are considered pathognomonic for measles. ${ }^{3}$ They may spread to cover the buccal and labial mucosa and the hard and soft palate.

Although a safe and effective measles vaccine was developed in 1963 and was eventually included in the trivalent measles-mumpsrubella vaccine in 1981 in the Greek National Vaccination Program, this patient had not been vaccinated against measles as a child or as an adult.

\section{CLINICAL DIFFERENTIAL DIAGNOSIS}

Once exanthem appears, the differential diagnosis for measles includes varicella, roseola (human herpesvirus 6 and 7), enteroviruses (coxsackievirus A9 and B5), erythema infectiosum (parvovirus B19), rubella, infectious mononucleosis, Epstein-Barr virus (especially during amoxicillin treatment), and group $\mathrm{A}$ streptococcal infection. 
If dyspnea develops, the differential diagnosis may encompass Rocky Mountain spotted fever, meningococcemia, and Mycoplasma pneumoniae-induced rash and mucositis. In immunocompromised individuals like this patient, the differential diagnosis also includes Candida albicans mucositis with subsequent fungemia and pneumonia, and herpes simplex virus type 1 infection with viremia and endorgan disease.

The presence of Koplik spots along with the symptoms typical for viral infection makes measles the most likely diagnosis even before the development of exanthem.

\section{SUPPORTIVE TREATMENT IS THE STANDARD}

The mainstay of measles treatment is supportive. Treatment of bacterial superinfections such as bacterial pneumonia and otitis, as well as seizures and respiratory failure, may also be necessary. Administration of vitamin A to children with measles is associated with decreased morbidity and mortality. ${ }^{4}$

Early initiation of ribavirin treatmentwithin the first 5 days of disease onset-seems more effective than later in the disease course. ${ }^{5}$ Given the high risk of measles-associated mortality in immunosuppressed individuals ${ }^{6}$ and the absence of treatment guidelines, some authors have recommended ribavirin treatment in patients with measles complications (mostly pneumonitis and encephalitis). ${ }^{5}$

In a prospective study of 100 patients with measles, half were assigned to treatment with ribavirin and supportive therapy, and the other 50 patients received only supportive therapy. Those receiving ribavirin had earlier resolution of fever and constitutional symptoms and fewer complications than those receiving only supportive care.?

The optimal duration of ribavirin therapy is not known, but 5 to 7 days may be reasonable except for severely immunosuppressed patients, who may require 2 to 3 weeks of treatment. $^{8}$

\section{TEACHING POINT}

In patients with short-term high fevers and symptoms of viral infection (eg, malaise, generalized myalgias, conjunctivitis) but no maculopapular rash, a thorough inspection of the buccal cavity for Koplik spots will allow for a timely diagnosis of measles and for prompt administration of ribavirin if dyspnea or other complications develop. ${ }^{4}$

\section{DISCLOSURES}

The authors report no relevant financial relationships which, in the context of their contributions, could be perceived as a potential conflict of interest.

\section{REFERENCES}

1. World Health Organization (WHO). Measles. https://www.who.int/ news-room/fact-sheets/detail/measles. Accessed November 3, 2021.

2. Porter A, Goldfarb J. Measles: a dangerous vaccine-preventable disease returns. Cleve Clin J Med 2019; 86(6):393-398. doi:10.3949/ccjm.86a.19065

3. Strebel PM, Orenstein WA. Measles. N Engl J Med 2019; 381(4):349_ 357. doi:10.1056/NEJMcp1905181

4. Huiming $\mathbf{Y}$, Chaomin W, Meng $\mathbf{M}$. Vitamin A for treating measles in children. Cochrane Database Syst Rev 2005; 2005(4):CD001479. doi:10.1002/14651858.CD001479.pub3

5. Roy Moulik N, Kumar A, Jain A, Jain P. Measles outbreak in a pediatric oncology unit and the role of ribavirin in prevention of complications and containment of the outbreak. Pediatr Blood
Cancer 2013; 60(10):E122-E124. doi:10.1002/pbc.24575

6. Misin A, Antonello RM, Di Bella S, et al. Measles: an overview of a re-emerging disease in children and immunocompromised patients. Microorganisms 2020; 8(2):276. Published 2020 Feb 18. doi:10.3390/microorganisms8020276

7. Pal G. Effects of ribavirin on measles. J Indian Med Assoc 2011; 109(9):666-667. pmid:22480102

8. Liatsos GD. Controversies' clarification regarding ribavirin efficacy in measles and coronaviruses: comprehensive therapeutic approach strictly tailored to COVID-19 disease stages. World J Clin Cases 2021; 9(19):5135-5178. doi:10.12998/wjcc.v9.i19.5135

Address: George D. Liatsos, MD, PhD, Department of Internal Medicine, "Hippokration" General Hospital, 114 Vass. Sophia's Avenue, TK 11527 Athens, Greece: geoliatsos@yahoo.gr 